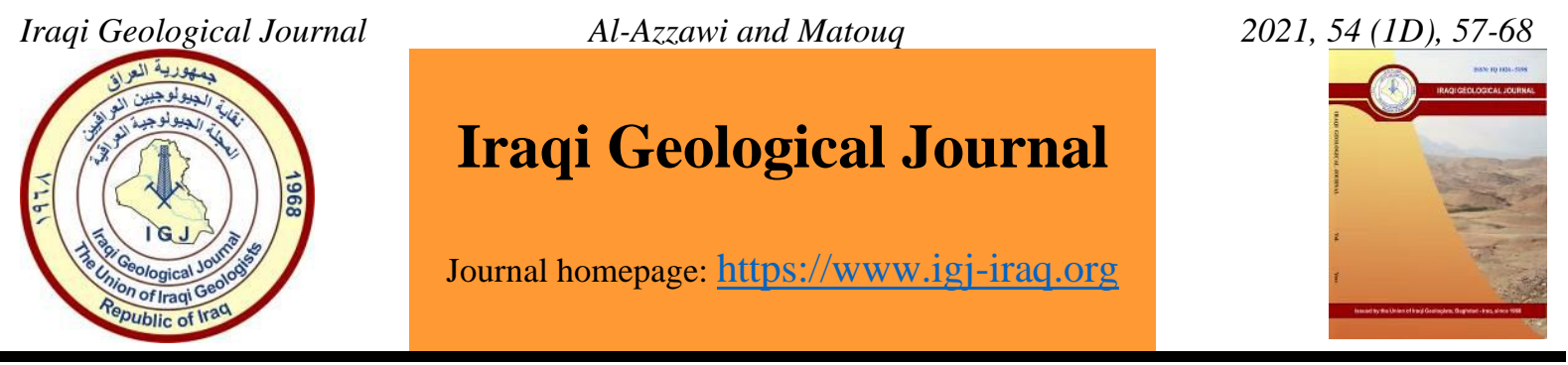

\title{
30 Years Climate Change Impact on Weather Elements and Green Coverage: GIS and Remote Sensing Geo-Environmental Case Study in Jordan
}

\author{
Thair Mudher F. Al-Azzawi ${ }^{1, *}$ and Mohammed Matouq ${ }^{2}$ \\ ${ }^{1}$ Department of Geography, College of Education for Women, University of Baghdad, Baghdad, Iraq \\ ${ }^{2}$ International Research Center for Water Environment and Energy, Al-Balqa Applied University, Jordan \\ *Correspondence: thaer.m@ coeduw.uobaghdad.edu.iq
}

Received: 31 December 2020; Accepted: 13 February 2021; Published :30 April 2021

\begin{abstract}
This study deals with climate change and its geo-environmental impact in Jordan for thirty years period (19822012). It comprised the building of a geographic information system (GIS) database for the most important basic climatic elements of temperature, rainfall, and relative humidity. Data is obtained from the Meteorological Department of Jordan for the study period. Digital descriptive and statistical analysis methods for the GIS database are implemented using ArcGIS 10.4 software and Normalized Difference Vegetation Index extracted from Moderate Resolution Imaging Spectroradiometer satellite images to forecast that impact on weather elements and green vegetation cover, respectively. Three different criteria are used for analysis and verification to achieve the objectives of the study. The criteria are the average annual minimum and maximum temperature, which is considered the most important criterion for this study, average annual rainfall, and average annual relative humidity. Results showed a speedy increase in the annual rate of the local temperature, particularly since 1990. Despite the local temperatures' average volatility, the increment reached about $1.5-2.0{ }^{\circ} \mathrm{C}$ degrees Celsius. An increase in the relative humidity is observed, but with no evident change in the average annual rainfall, both in Jordan's northern and eastern parts. At the same time, there were increases for Jordan's central region during the period 1985-2012. The green vegetation cover area showed a decrease during the studied period 2002-2008 as that is probably due to the evident increase in annual average temperature and evaporation. Results reveal the increase of the greater temperature change region has increased in the northern part of Jordan by eight times for the 19822002 period as mentioned in this study. The area of vegetated area decreased to $3725.8 \mathrm{~km}^{2}$ in 2008 compared to $9305.5 \mathrm{~km}^{2}$ in 2002 . The study demonstrated efficiency in applying descriptive and statistical GIS analysis methods on the climatic database, which better understanding of the climate change phenomenon.
\end{abstract}

Keywords: GIS; Remote sensing; Normalized Difference Vegetation Index; Climatic elements

\section{Introduction}

Climate change occurs due to different climatic conditions, either because of the dynamic processes of the earth or because of the industrial activities of humans, especially after the industrial revolution (Nawal and Mustafa, 2017). Climate change is among the regional challenges facing the Middle East region since the last century. It had significant effects on the agricultural, urban, environmental, economic, social, and health aspects. Those effects impacted clearly and directly the amount of precipitation, soil erosion, desertification, and drought. They have greatly affected the

DOI: $\underline{10.46717 / \text { igj.54.1D.5Ms-2021-04-25 }}$ 
potential for cultivation and the availability of arable land and crops, in addition to the three most significant trends of concern to humans: population growth, urbanization, and increased demand for water and food. The greatest danger that the Middle East faces is the decrease in the amount of rain due to global warming in a region already suffering from water scarcity, as this region inhabits about 5\% of the world's population, but it only has $1 \%$ of the global water reserve (MOE, 2006; UNEP, 2006). Jordan, with many governmental committees in the countries of the world, and the Intergovernmental Panel on Climate Change (IPCC) has carried out several studies that indicated that those climate factors are inseparable from the essential factor's survival. The effects of climate change cannot be isolated from the future of food security policies in the Middle East and the world, especially in countries that share common characteristics and features such as climate change problems water scarcity, soil erosion, desertification, droughts and floods. Jordan is one of the most affected Middle East countries by climate change (ESCWA, 2005). In 1999, The Hashemite Kingdom of Jordan became a member of the United Nations Framework Convention on Climate Change (UNFCCC) which stipulates the necessity of coming up with plans to decrease global warming and adapt to every rise in inevitable temperatures to reach the minimum provided in the Kyoto Protocol (Niles, 2006). On the other hand, integration and analysis of GIS and Remote Sensing data have become a trend for environmental assessment and management for its capabilities of manipulating and managing a large amount of spatial data to satisfy policymaker and planner growing needs for accurate land use and land cover changes information (Yuan, 2008). Remote sensing technology is characterized by a record speed and a large comprehensiveness to study the Earth's surface features and surroundings, where surveys achieve large areas with a standard time and provide a frequent survey at different dates (Al Ramahi and Al Bahadly, 2020). Many climate change studies presented several results which indicate temperature increases caused by the rapid increase in the daily minimum temperature compared to the slow decline in the daily maximum temperature, which decreases according to the decrease in daytime temperatures (Diurnal Temperature range; DTR). This is noticeable in large areas of the United States of America, as it is noticed that trends in large areas where maximum temperatures increase slowly. In contrast, minimum temperatures increase rapidly (Karl et al. 1990). In studies similar to other regions, it showed seasonal fluctuations in high and low temperatures such as the study of Philaudras et al. (1999), that were conducted on four large Turkish cities showed that the phenomenon of regional warming is the strongest in spring and the weakest in autumn and winter. It was also revealed that the phenomenon of urban warming is more or less throughout the year with a scarce increase in the months of the autumn season.To develop a valued decision-support system for climate alteration policy and planning, Javadinejad et al. (2020) presented an integrated climate change, water/energy modeling platform which allows tailored climate alteration and water-energy assessments. This was to recognize the impacts of climate variability (changes in temperature and precipitation) on water and electricity consumption in Zayandeh Rud River Basin (Central Iran) for the period (1971-2005) and future period (2006-2040). Climate models have projected that the temperature will increase by $7^{\circ} \mathrm{C}$ and precipitation will decrease by $44 \%$, and it is also proposed that electricity imports will rise during a severe dry scenario in the basin, while power generation will decrease by around $8 \%$. Studies focused on Jordan revealed that climate change poses a real threat to the country because most of the water resources and water ecosystems depend heavily on the hydrological cycle and climate conditions. Climate changes have a tremendous and rapid impact on irrigation needs, as the change in annual rainfall by $1 \%$ cusses a change in the demand for irrigation by $5 \%$. Increasing the temperature to more than $2^{\circ} \mathrm{C}$ versus an increase in the rate of evaporation by $15 \%$ will lead to an increase in the demand for irrigation water by about $18 \%$, for example, but not limited to, when the rainfall decreases by $10 \%-20 \%$, wheat production decreases by equivalent to 8.5 and 15 thousand tons respectively (ESCWA, 2005). The need to explore the climate change impacts on Jordan, especially on water resources, will be of great help for calculating the water balance at the country level and will be of great help to decision-makers in the field of environment in 
Jordan (Domi, 2005; Abdulla and Al-Omari, 2008). The study of Al-Omari et al. (2011) showed the impacts of the proposed red dead canal (RDC) project on bridging the gap between supply and demand in Amman and Zarqa cities within Amman Zarqa Basin (AZB) and in the Jordan Valley. Also, the study expected Climate change is the climate changes to reduce resources and increase demands which will inevitably result in enlarging the gap between supply and demand. Reconciliation to these impacts can be achieved either by developing and utilizing undeveloped resources or by reducing demands via implementing demand management practices, or by both. The aims of this study deal with climate change and its geo-environmental impact in Jordan as it has three main objectives such as studying the possibility and effectiveness of applying Remote Sensing and GIS technologies for studying climate change phenomena, mainly predicting the geo-environmental effect of global warming on Jordan, states importance of the GIS technique's to calculate and cartograph the area's representation shown in a regional temperature change, amount of rainfall and humidity related to the availability of those data at the Meteorological Department of Jordan, besides using many spatial analyzing methods of GIS to manipulate the climatic data to analyze the climate change in the region and to inspect the impact of climate changes on the weather elements during thirty-year period 1982-2012 in Jordan, Studying the impact of selected weather elements on green vegetation coverage in Jordan during 2002-2008 by applying Normalized Difference Vegetation Index (NDVI) extract from Moderate Resolution Imaging Spectroradiometer (MODIS) satellite images.

\section{Data and Methodology}

The data used for building the database and the analysis processes in this study were obtained from the Jordan Meteorological Department. They included records of the monthly average, seasonal and annual average of temperature, daily minimum and maximum temperatures (the temperature is considered the most important factor in this study's approach), rain, and humidity percentage. Generally, this data has covered about three decades for the 1982-2012 period. Unfortunately, this study does not have a recent data; there are differences in the periods of gained data for the three climate elements related to the availability of those data at the Meteorological Department of Jordan. In this case study, available data can be suitable for the analysis and manipulation to analyze the climate change in the region. Those data are extracted for 13 climate stations widely distributed in the country. The names and locations of the chosen climate stations for this study are marked on the digitally produced map of Jordan with accurate coordinates (Fig. 1).

Three main climatic variables for the analysis process are focused on achieving the objectives of the study. Those are:

- The annual average of the maximum and minimum temperatures.

- The annual relative humidity.

- The average annual rainfall.

All data are entered into the ArcGIS 10.4 application and re-displayed to create views for each of the three climatic variables for different periods. To ease analysis the location map of Jordan is divided into four regions according to their terrain characteristics (Fig. 1), as follows:

- The Jordan Valley (Drift valley) region occupies about $8.5 \%$ of the Jordan area (the Jordan area is $89,342 \mathrm{~km}^{2}$ ). This part includes the area extending from the Dead Sea to the city of Aqaba south.

- The mountain region occupies about $4.8 \%$ of the Jordan area. This part mainly includes the central and northern regions of Jordan.

- Facile (central) region includes about $11.3 \%$ of the Jordan area.

- The desert region occupies most of Jordan's southern and eastern parts and is estimated to form about $75.4 \%$ of the Jordan area. 
According to those four location regions division data are discussed, analyzed, and classified for the 1982-2012 period.

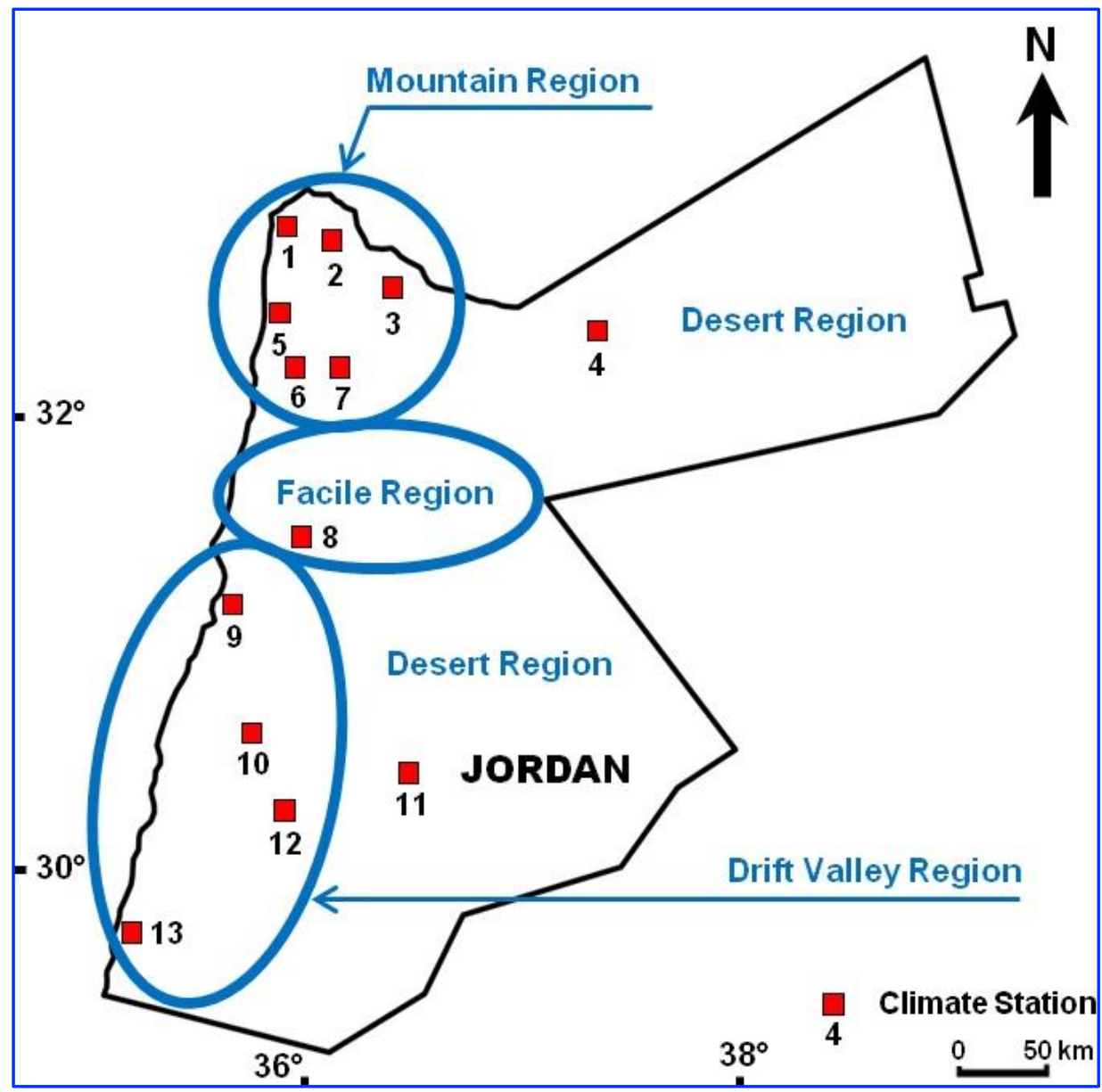

Fig.1. Jordan's four location region divisions and selected regional climate stations: Al Baqura, Irbid, Muniyfeh, As Safawi, Dyralla, As Salt, Al Jubayhan, Ar Rabba, Assafi, Ash Shoubak, Al Jafr, Ma'an and Al Aqabah

The methodology comprised the study's data by applying two basic spatial analysis concepts and modeling in GIS technology. The first is the dynamic model which is commonly used in constructing environmental models that depends on the time factor for clarifying changes of the spatial and attributes data. The second model is the prescriptive model which depends on the future prediction of spatial data conditions (Al-Azzawi, 2008). The database was analyzed by the following techniques using two types of common GIS analysis methods:

\subsection{Attributes or Properties Analysis}

In this type of analysis, the attribute data tables in the geodatabase are used to conduct statistical and logical analysis on the descriptive data of the layers, such as elements of temperatures, relative humidity, rainfall, and review for each of the four regions. The geographic information system sends inquiries to the database and the system returns the answer and displays the numbers and statistics that meet the criteria determined by the questions. Answers are specified in the tables or on the map. The fact that the database contains similar elements or phenomena will make the use of this type of analysis more manageable and effective. Similarity means that the analysis is for the same geographical area and with several layers that contain different variables (layers) such as the elements of temperature, relative 
humidity, and rainfall. There is no need to use maps to perform this type of analysis, but sometimes maps and layers can be used according to the need to show the results of the analysis results.

\subsubsection{Statistical analysis}

This spatial analysis method relies on the descriptive and spatial database for performing statistical calculations related to the temperature zone area for each of the four regions according to their topographical characteristics. Analysis of the impact of climate change on them is performed by comparing their current and previous areas and representing results by graphs to predict climate and environmental changes caused by global warming. On the other hand NDVI maps were generated and used to produce sequential vegetation cover maps from the available images of MODIS $-1 \mathrm{~km}$ resolution MODIS satellite images which used the band Near Infra-Red (NIR) is band 2, and Red is band 1 for all images. The produced maps show the change on the green vegetation cover in the study area during the period 2002-2008. MODIS images are used to improve our understanding to predict global climate change accurately enough and inspect related impact on environment.

\section{Results and Discussion}

\subsection{Annual Average Minimum and Maximum Temperature}

The annual average values of the minimum and maximum temperatures for the years 1982, 1987, $1992,1998,2002$ analysis for the desert region is given in Table1. This table shows an increase of $1.5^{\circ} \mathrm{C}$ in the southern and eastern parts of Jordan; most of that area is in the desert region. Simultaneously, the annual average of minimum temperatures of this region for the same period also increased by $1.5^{\circ} \mathrm{C}$. The analysis results showed that there are changes in the annual average temperature of the maximum temperatures as they increased from $28.5^{\circ} \mathrm{C}$ to $31.5^{\circ} \mathrm{C}$. Also, the annual mean minimum temperatures increased from $16.5^{\circ} \mathrm{C}$ to $18.5^{\circ} \mathrm{C}$. To give a spatial perception of the temperature change detection during the same period, the areas of the temperature change zones (the temperature zone area ) for each region were calculated using the spatial statistical analysis method in the ArcGIS 10.4 application. They were calculated in square kilometers of the desert region with study periods and represented by bar diagrams. Fig. 2 shows that in 1982 the annual maximum temperature is $28.5^{\circ} \mathrm{C}$ measured in an area of approximately $68,000 \mathrm{~km}^{2}$. This temperature zone area decreased for 2002 to $25,000 \mathrm{~km}^{2}$ and the annual maximum temperature increased to $31.5^{\circ} \mathrm{C}$. This indicates that the desert region fell under the influence of the global thermal rise in 2002 compared to 1982.

Table 1. Annual maximum and minimum temperatures in the desert region for the 1982-2002 period

\begin{tabular}{lllll}
\hline Year & $\mathbf{1 9 8 2}$ & $\mathbf{1 9 8 7}$ & $\mathbf{1 9 9 8}$ & $\mathbf{2 0 0 2}$ \\
Maximum temperature $\left({ }^{\circ} \mathrm{C}\right)$ & $>28.5$ & $>30$ & $>31.5$ & $>31.5$ \\
Minimum temperature $\left({ }^{\circ} \mathrm{C}\right)$ & $>16.5$ & $>16.5$ & $>18$ & - \\
\hline
\end{tabular}

The same methods of analysis were used and repeated in the northern region. The attribute data tables analysis results for the minimum and maximum temperatures in that region are presented in Table 2. There is an apparent increase in the annual average temperature for the period from 1982-2002, and an increase in the annual average temperature of $1.5^{\circ} \mathrm{C}$ from 22.5 To $24^{\circ} \mathrm{C}$, respectively. For the same period, the annual average minimum temperature increased from $12^{\circ} \mathrm{C}$ to $13^{\circ} \mathrm{C}$. The temperature change zone area was calculated for the northern region, and it was found that it has increased in this region from $5,000 \mathrm{~km}^{2}$ to $40,000 \mathrm{~km}^{2}$ Fig. 3. This gives a clear indication that the greater temperature change region has increased in the northern part of Jordan by eight times for the 1982-2002 period. 


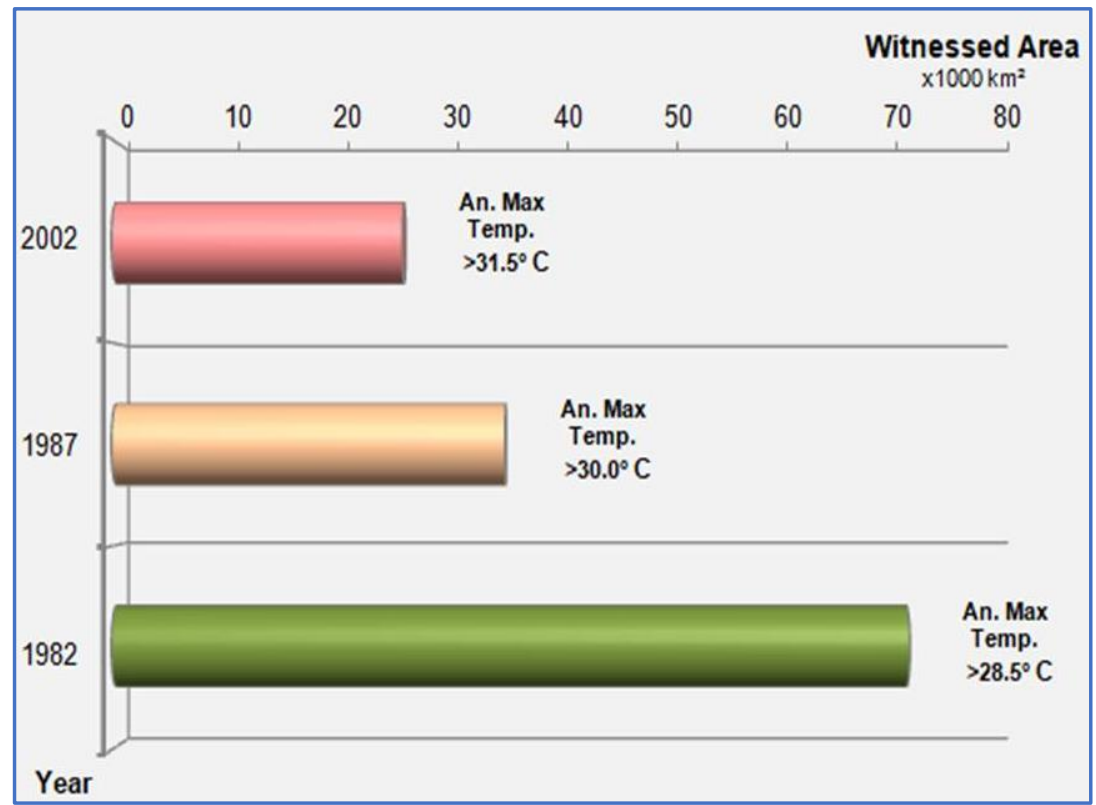

Fig.2. GIS calculated desert areas and annual maximum temperature for the 1982-2002 period. (The X axis represents witnessed affected areas for measured temperature)

Table 2. Annual maximum and minimum temperatures in the northern region for the 1982-2002 period

\begin{tabular}{llcccc}
\hline Year & $\mathbf{1 9 8 2}$ & $\mathbf{1 9 8 7}$ & $\mathbf{1 9 9 2}$ & $\mathbf{1 9 9 8}$ & $\mathbf{2 0 0 2}$ \\
\hline Maximum temperature $\left({ }^{\circ} \mathrm{C}\right)$ & $22.5-24$ & $22.5-24$ & $24-25.5$ & $24-25.5$ & $24-25.5$ \\
Minimum temperature $\left({ }^{\circ} \mathrm{C}\right)$ & $12-13.5$ & $12-13.5$ & $13.5-15$ & $13.5-15$ & - \\
\hline
\end{tabular}

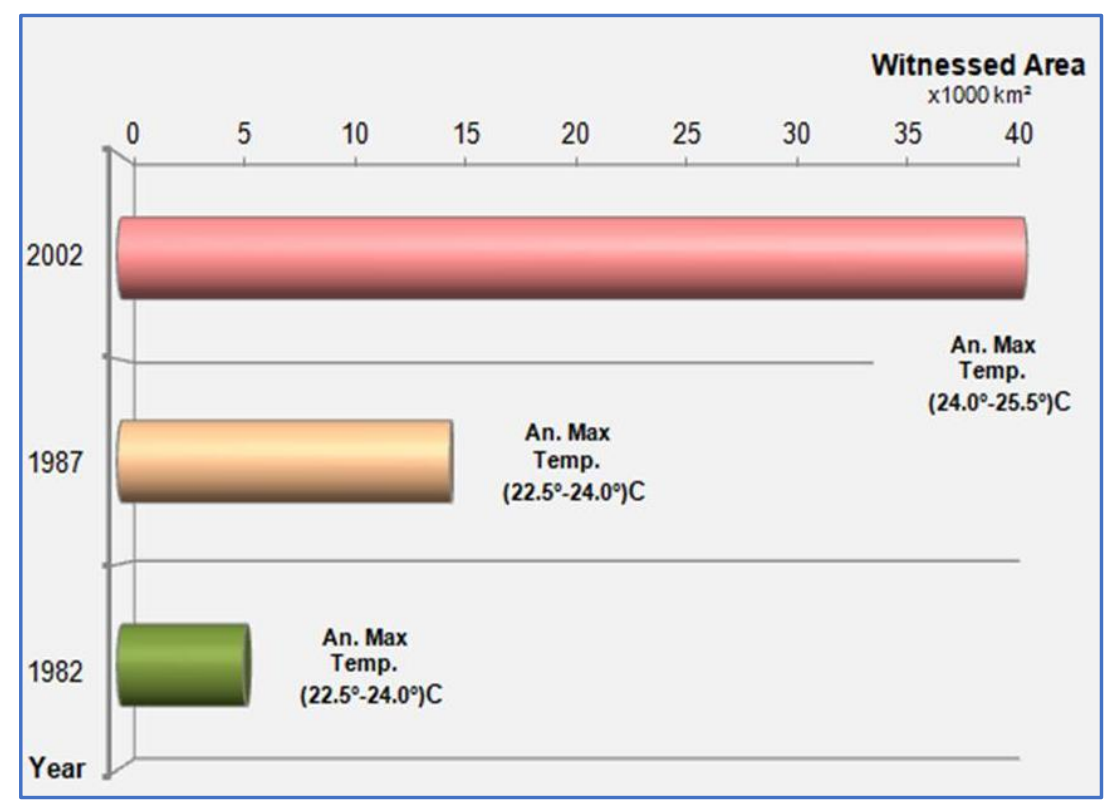

Fig. 3. GIS calculated northern region areas for annual average maximum temperature for 1982-2002 period

In the facile region (central part) of Jordan (includes the capital Amman), the annual average of maximum and minimum temperatures is calculated from the database's attribute data tables. The results showed in Table 3 indicate that there is a $3^{\circ} \mathrm{C}$ increase in the annual average temperature for the period 
1982-2002. It is also noticed that the annual average minimum temperatures exhibited the same behavior in terms of increase by $1.5^{\circ} \mathrm{C}$ for the same period.

Table 3. Annual maximum and minimum temperatures in the facile (central) region for 1982-2002 period

\begin{tabular}{lccccc}
\hline Year & $\mathbf{1 9 8 2}$ & $\mathbf{1 9 8 7}$ & $\mathbf{1 9 9 2}$ & $\mathbf{1 9 9 8}$ & $\mathbf{2 0 0 2}$ \\
\hline Maximum temperature $\left({ }^{\circ} \mathbf{C}\right)$ & $22.5-24$ & $24-25.5$ & $24-25.5$ & $25.5-27$ & $25.5-27$ \\
Minimum temperature $\left({ }^{\circ} \mathbf{C}\right)$ & $7.5-9$ & $9-10.5$ & $9-10.5$ & $9-10.5$ & $9-10.5$ \\
\hline
\end{tabular}

The area of the facile (central) region's temperature change zone is calculated for different periods. Fig. 4 shows an increase from $3,000 \mathrm{~km}^{2}$ in 1982 to $8,000 \mathrm{~km}^{2}$ in 2002 . This area increase is incremental in this region with time, as the local population living in the region confirmed that according to their real sense. Perhaps the rapid urban expansion factor has also played an essential role in increasing temperatures.

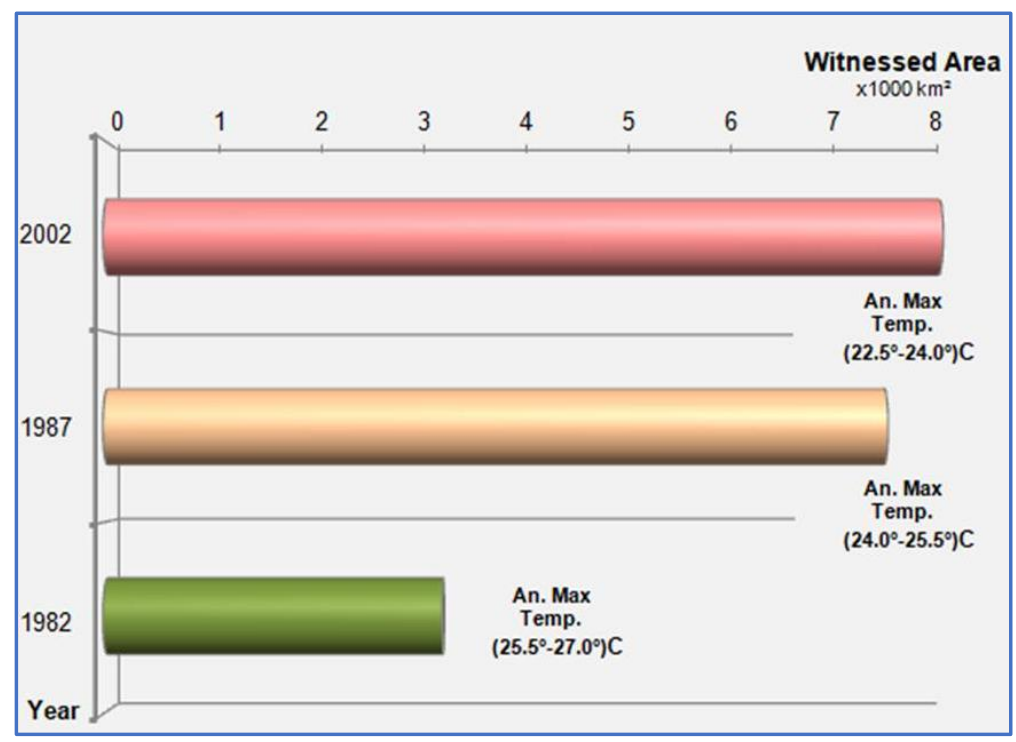

Fig. 4. GIS calculated facile (central) region areas and annual average maximum temperature for the 1982-2002

\subsection{Relative Humidity Distribution}

The annual distribution of relative humidity is analyzed from the data available in the Jordan Meteorological Department. It was used to study the climate change effects on the relative humidity in the study area. Available data were for the 1982 to 1995 period only. The method of analyzing attribute data tables by ArcGIS 10.4 is used. Table 4 shows that there is $46.5 \%$ to $50 \%$ increase in relative humidity in eastern parts (rift valley region) and southern parts of Jordan (desert region). As for the facile (central) region, there is fluctuation in relative humidity in 1982, which amounted to about $60 \%$. It declined to its lowest rate of about 55\% in the 1987-1990 period, while its highest rate of $61 \%$ is in 1995. The main reason for the increase of relative humidity in eastern part of Jordan especially rift valley region, is due to its geographic proximity to the Dead Sea, $400 \mathrm{~m}$ below sea level. Moreover, there is no effect on increasing relative humidity in the whole region of Jordan for its distance from Dead Sea. Its height above sea level, such as Amman city in the central region which situates almost $800 \mathrm{~m}$ above sea level. There is a complete and robust direct relationship between the value of relative humidity and the amount of rain precipitation, as the higher relative humidity means high rain and the lower relative humidity means less rain. It can be generally concluded that the relative humidity value decrease to $15 \%$ means that the season is arid. 
Table 4. Annual average relative humidity in the study area for 1982-1995 period

\begin{tabular}{lcccc}
\hline Year & $\mathbf{1 9 8 2}$ & $\mathbf{1 9 8 7}$ & $\mathbf{1 9 9 0}$ & $\mathbf{1 9 9 5}$ \\
\hline Northern region (\%) & $58.5-60$ & $56-57.5$ & $52.5-54$ & $>62$ \\
Facile (central) region (\%) & $61.5-63$ & $54.5-56$ & $57-58.5$ & $60-62$ \\
Desert region (\%) & 46.5 & $<40.5$ & $<42$ & $<50$ \\
\hline
\end{tabular}

\subsection{Rainfall}

Available data of the annual rainfall rate in Jordan were calculated for the periods 1985, 1990, 1996, 2002, 2005 (Table 5). The attribute table analysis for the annual rate of rainfall in the desert region shows that this rate remained stable for the period from 1985 to 2005 which is estimated to be more than $50 \mathrm{~mm}$. Therefore, the amount of rain in this area remained minimal. It is also clear from Table 5 and the availability of archive data- that the rainfall has increased in the desert region by a small amount more than $50 \mathrm{~mm}$ in 1996 compared to the year 1985 and that agrees with the increasing from $46.5 \%$ to $50 \%$ in relative humidity in the desert region for the 1982 to 1995 period. The local population in this region noted that the amount of rain has increased in this period and this is due to the increase in temperature that this study touched upon previously and led to an increase in the rate of evaporation as well as.

Table 5. Annual rainfall in the study area for 1985-2005 period

\begin{tabular}{lcccc}
\hline Year & $\mathbf{1 9 8 5}$ & $\mathbf{1 9 9 6}$ & $\mathbf{2 0 0 0}$ & $\mathbf{2 0 0 5}$ \\
\hline Desert region & $>50$ & $>50$ & $>50$ & $>50$ \\
Northern region & $350-400$ & $350-400$ & $350-400$ & $350-400$ \\
Facile (central) region & $400-450$ & $400-450$ & $450-500$ & $450-500$ \\
\hline
\end{tabular}

As for the northern part of Jordan is the best agricultural areas, it is noted from Table 5 that the annual rainfall rate has remained constant for 1985-2005 period and at an annual average of $400 \mathrm{~mm}$. In the facile (central) region, it is noted from Table 5, the annual rainfall rate has increased by $50 \mathrm{~mm}$ for 1996-2005 period and that agrees with the increasing of the highest value of relative humidity $(61 \%)$ in 1995 , as this was approximately rate.

\subsection{NDVI}

NDVI derived from remotely sensed measurements of electromagnetic energy in the red and nearinfrared spectral regions. It is used for determining and monitoring the density of green vegetation cover area on a patch of land it is a must to observe the distinct colors (wavelengths) of visible and nearinfrared sunlight reflected by the plants using satellite data. NDVI images were generated using an algorithm as in the following equation (Jasim, 2012; Elmore et al., 2000):

$$
N D V I=\frac{N I R-R}{N I R+R}
$$

Where for MODIS data, Near Infra-Red (NIR) is band 2, and Red is band 1 for all images. NDVI images were generated for all dates using equation1.

\subsection{Climate Change Impacts on the Green Coverage in Jordan}

A subset of each of MODIS digital images acquired in April 2002, 2003, 2004 and 2008 covering the whole Jordan were used. All images were supplied by USGS, had already been rectified and georeferenced to UTM map projection (Zone 36), and WGS84 ellipsoid. The digital images were 
radiometrically calibrated to each other to facilitate their comparison. Since all images were acquired in the same season. A histogram matching provided by PCI software had been used in this study. After this correction, images statistics and histograms from the four periods were found to be similar and comparable. The NDVI maps were used to detect, estimate and monitor the green vegetation coverage area for years 2002, 2003, 2004 and 2008 (Fig. 5). Areas were calculated based on pixel numbers for green vegetation cover areas related to the number of pixels for the non-vegetated areas (Table 6). Generally, it is obvious that the green cover area has decreased from 2002 to 2008 respectively, as the area of vegetated area decreased to $3725.8 \mathrm{~km}^{2}$ in 2008 compared to $9305.5 \mathrm{~km}^{2}$ in 2002 . This decrease is possibly linked with the general increase in the average temperature and evaporation and that agrees with the greater temperature change region increase in the northern part of Jordan by eight times for the 1982-2002 period as mentioned above, and that's a good indicator for the climate change in this period. The annual average temperature increase of $1 \mathrm{C}^{\circ}$ degree means a big daily effect on Jordan, and that is as same as of the climate change issue observed globally. Also, the local populations are feeling and noted the change in many regions recently, that as this change has occurred in conjunction with the evident climate change in Jordan.

Table 6. Areas of vegetated and non-vegetated $\left(\mathrm{km}^{2}\right)$ in Jordan for 2002, 2003, 2004 and 2008 period were calculated based on of pixel numbers

\begin{tabular}{cccc}
\hline Year & vegetated area $\mathbf{~ k m}^{\mathbf{2}} \%$ & Vegetated area $\mathbf{~ k m}^{\mathbf{2}}$ & Non- vegetated area $\mathbf{~ k m}^{\mathbf{2}}$ \\
\hline 2002 & 10.416 & $9,305.86$ & $80,036.14$ \\
2003 & 8.192 & $7,318.90$ & $82,023.103$ \\
2004 & 3.396 & $3,034.05$ & $86,307.946$ \\
2008 & 4.17 & $3,725.56$ & $85,616.439$ \\
\hline
\end{tabular}

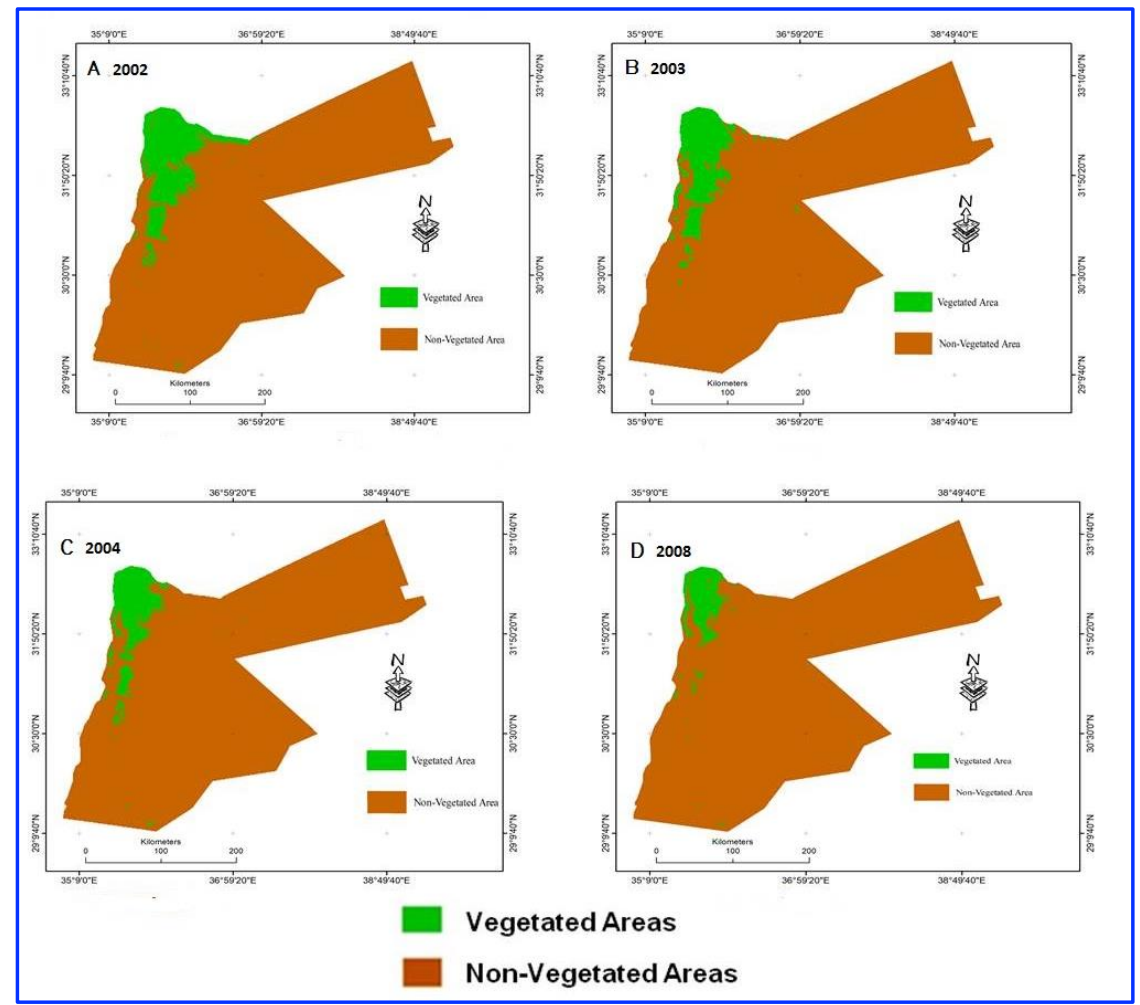

Fig. 5. NDVI maps produced by spatial analyst interface of ArcGIS 10.4 show a decrease of vegetated green coverage area in Jordan due to climate change for April 2002 (A), 2003 (B), 2004 (C), and 2008 (D) period respectively (areas were calculated and colored according to pixel numbers) 


\section{Conclusions}

- The study demonstrated the possibility and effectiveness of applying descriptive and statistical analysis methods in GIS and remote sensing technologies to study climate change phenomena, particularly predicting the geo-environmental effect of global warming on Jordan. Moreover, the GIS technique contributed to the high accuracy calculation of areas and show a regional change in temperature and amount of rainfall for every year during the period 1982-2012 to reach a better view, understanding and accuracy to demonstrate these geo-environmental relationships.

- The study relied on the Jordan Meteorological Department data, which was analyzed and showed interesting results. The results indicated that there are apparent changes in the annual average of minimum and maximum temperatures throughout Jordan from 1982 to 2002. The increase in the temperature is around $1.5-2.0^{\circ} \mathrm{C}$. If this increase in temperatures continues in the same rise in the next years, it will lead to an unacceptable and dangerous situation compared to the global level.

- Analysis of the minimum and maximum mean near the surface temperature recorded in 13 climatic stations in Jordan for the 1982 to 2002 period has detected the details of the spatial and temporal climatic patterns. It revealed long-term trends of high or low temperatures at different periods and locations. Increasing the annual minimum temperatures of the facile (central) region of Jordan gives a clear and important signal indicating the presence of climate warming in Jordan's urban areas.

- This state of instability in the distribution of temperature and fluctuation will lead to Jordan experiencing heat waves at different times during the year. Also, heavy rain is expected in variable quantities in different regions and not necessarily falling during the rainy season.

- Due to the rise in both the high and minimum temperatures, the rate of evaporation also began to increase, which led to an increase in the percentage of humidity in Jordan. This is most common in the northern part where the amount of precipitation is high in this region.

- The general results indicated that there is no change in the annual rate of rainfall in the northern and eastern parts of Jordan, while an increase is observed in the central region for the 1985 to 2005 period. The reason for this increase might be related to the increase in temperature that this study touched upon previously and led to an increase in the rate of evaporation.

- The amount of rain in Jordan tends to increase and within the limits of $20 \mathrm{~mm}$ annually. This leads to taking the necessary needs from now on for the possibility of floods. Therefore, the increase in the amount of rain leads to an enhanced evaporation rate, which in turn affects the natural cycle of water despite the increase in rainfall rates. However, this study noticed an increase in rain, but the rainy season may cause a shift. The signs of a possible climate change have been observed going forward.

- The study mentioned that the level of soil moisture is expected to increase in most Jordan due to the slight expected increases in rainfall especially in the central part of Jordan, compared to the expected increase in the evaporation rates due to the high and minimum temperatures.

- The green vegetation cover area showed a decrease during the studied period 2002-2008 as that is probably due to the evident increase in annual average temperature and evaporation and that agrees with the fact that the greater temperature change region has increased in the northern part of Jordan by eight times for the 1982-2002 period. The zone of vegetated area decreased to $3725.8 \mathrm{~km}^{2}$ in 2008 compared to $9305.5 \mathrm{~km}^{2}$ in 2002 . Moreover, that's a good indicator of climate change in this period. The local population noted that this change has occurred in conjunction with the evident climate change in Jordan.

- Most of the previous studies showed that the climate conditions have changed significantly during the past years in the regional and global levels. This change corresponds with the effect of global warming on Jordan's climate, as it began to be observed and recorded especially after the year 1990. Therefore, the effect of warming is visible as a catalyst and supporter of the desertification process, which reflects the problem of diminishing and degradation of the green vegetation cover in Jordan. 
- This study might guide similar and complementary studies in the Middle East neighboring countries as the climatic change issue is no longer local but became regional and global. This is in line with globalization in solving problems of a global dimension, as there is a gap in the balance for the benefit of globalization, especially in the field of climate change and geo-environmental impacts.

\section{Acknowledgements}

We sincerely thank the Royal Jordanian Geographic Center for providing the updated digital maps of Jordan. Thanks and gratitude goes also to the Jordanian Meteorological Department for providing the weather station data for this study. The authors are very grateful to the Editor in Chief Prof. Dr. Salih M. Awadh, the Secretary of Journal Mr. Samir R. Hijab. and the Technical Editors for their great efforts and valuable comments.

\section{References}

Abdulla, F. A., Al-Omari, A., 2008. Impact of climate change on the monthly run-off of semiarid catchments: case study Zarqa River Basin (Jordan). Journal of Applied Biological Sciences, 2 (1), 43-50.

Adel, H. V., 1996. Conservation et Gestion del' Eau dans les pays entourant Sahara. In: water resources management and desertification: problems and challenges. World Meteorological Organization, Geneva: $242-264$.

Al-Azzawi, T. M., 2008. Introduction to GIS and Data with ArcView GIS application. First ed. Al-Hamid house for publication and distribution. Amman, Jordan. (In Arabic), $310 \mathrm{pp}$.

Al-Billbisi, H. H., Makhamreh, Z. M., 2010. A Comparison of pixel-based and object-based classification approaches in arid areas of Dead Sea Region using landsat imagery, Journal of Dirasat, 37 (3), 649-659.

Al-Omari, A., Salman, A., Karablieh, E. 2013. The red Dead Canal project: an adaptation option to climate change in Jordan. Desalination and Water Treatment, 10(1080), 1-8.

Al Ramahi, F. K. M., Al Bahadly, Z. K. I., 2020. The spatial analysis for Bassia eriophora (Schrad.) Asch. plant distributed in all Iraq by using RS \& GIS Techniques. Baghdad Science Journal, 17(1), 126-135.

Chung. U., Choi, J., Yun, J. L., 2000. Urbanization effect on the observed change in mean monthly temperatures between 1951-1980 and 1971-2000 in Korea, Climatic Change, 66, 127-136.

Domi, M. B., 2005. Trend analysis educational social sciences of temperatures and rainfall in Jordan, Umm AlQura University Journal of \& Humanities, 17 (1), 15-35.

Eischeid, J. K., Baker, C. B., Karl, T. R., and Diaz, H. F., 1995. The quality control of long-term climatologically data using objective data analysis, Journal of Applied Meteorology, 34, 2787-2795.

Elmore, A. J., Mustard, J. F., Manning, S. J., Lobell, D. B., 2000. Quantifying vegetation change in semiarid environments: precision and accuracy of spectral mixture analysis and the normalized difference vegetation index. Remote sensing environment, 73(1), 87-102.

ESCWA., 2005. Arab Region State of Implementation on Climate Change Economic and Social League of Arab State Commission for Western Asia, UN.

Hulme, M.,1991. An intercomparison of model and observed global precipitation climatologist, Geophysical Research Letters, 18, 1715-1718.

Jasim, A., 2012. Monitoring Desertification in Badra Area Eastern Iraq by Using Landsat Image Data, M.Sc. Thesis, Baghdad University.

Javadinejad, S., Hannah, D., Krause, S., Dara, R., Jafary, F., Naseri, M., .2020. The impacts of climate change on energy-Ate systems and economic analysis. Iraqi Geological Journal, 53(2F), 1-17.

IPCC., 1996. The Science of Climate Change Contribution of Working Group I to the Second Assessment Report of the Intergovernmental Panel on Climate Change, Houghton, J.J., L.G. Meiro Filho, B.A. Callander, N. Harris, A. Kattenberg and K.Maskell (eds.): Cambridge University Press, Cambridge and New York.

Karl, T. R., Kuklia, G., Gavin, J.,1990. Is recent climate change across the United States due to greenhouse gases, Journal of Geophysical Research, 95, 16617.

MOE., 2006. Environmental Profile of Jordan 2006, Jordan Ministry of environment March. 
Nawal, K. G., Mustafa, J. S., 2017. Detection and interpretation of clouds types using visible and infrared satellite images. Iraqi Journal of Physics, 15(34), 123-137.

Niels, H. B., 2006. Soil carbon stocks of Jordan and projected changes upon improved management of croplands, Geoderma, 132 (3-4), 361-371.

Nikolai, K., Tateishi, R., Gunin, P., Al-Bilbisi, H., 2004. Degradation of The Dry lands of Northern Africa, Center for Environmental Remote Sensing (CEReS), Chiba University, Japan.

Parker, D. E., Jones, P. D., Folland, C. K., Bevan, A., 1994. Interdecadal changes of surface temperature since the late 19th century. Journal of Geophysical Research, 99, 14373-14399.

Philandras, C. M., Metaxas, D. A., and Nastos, P. T., 1999. Climate variability and urbanization in Athens, Theoretical Applied Climatology, 63: 65-72.

UNEP, 2006. An overview of our changing environment, in: Paul Harrison (Ed.), Global Environment Outlook (GEO): Progress Press Ltd., Malta, 1-91.

Yuan, F., 2008. Land-cover change and environmental impact analysis in the Greater Mankato area of Minnesota using Remote Sensing and GIS modeling. International Journal of Remote Sensing, 29(4), 1169-1184. 